\title{
Changes on diametral compression behaviour of compacted marls due to drying
}

\author{
Carmen Covadonga Garcia-Fernandez, ${ }^{1, *}$, Rafaela Cardoso $^{2}$, Martina Inmaculada Alvarez-Fernandez ${ }^{1}$, and Celestino \\ Gonzalez-Nicieza ${ }^{1}$ \\ ${ }^{1}$ Dept. of Exploitation and Prospecting Mines, Mining Engineering School, University of Oviedo, Asturias, Spain \\ ${ }^{2}$ CERIS, ICIST, IST, Instituto Superior Técnico - University of Lisbon, Lisbon, Portugal
}

\begin{abstract}
Cracking due to desiccation can compromise the behaviour of earth structures built with compacted clayey soils by promoting water access and consequent volume changes on further wetting. Tensile strength therefore is important to be considered when studying the behaviour of such structures, and in particular its dependence on the degree of saturation or water content. The influence of water content in tensile behaviour of compacted marls was investigated by performing diametral compression tests (Brazilian splitting tests), where axial deformations were measured besides strength. The samples were prepared by compaction at optimum point using standard compaction energy (optimum water content 16\%) and then dried by vapour equilibrium to reach water contents between $5 \%$ and $16 \%$. The correspondence between water content and suction was done by using the drying branch of the water retention curve, measured using WP4 equipment (Water Dewpoint Potentiometer). Good relationships were found between tensile strength and the water content (and suction). In addition, the study was completed with the analysis of other parameters such as the semi-contact angle created in the loaded area and the stiffness of the material, which also showed changes with water content.
\end{abstract}

\section{Introduction}

Cracking due to desiccation can compromise the behaviour of earth structures built with compacted clayey soils, such as embankments and earth dams, by promoting water access and consequent volume changes on further wetting. This is an important property when calibrating numerical models, necessary to predict failure in case of flooding or long term performance of embankments when subjected to atmospheric actions.

Tensile strength therefore is important to be considered when studying the behaviour of such structures, and in particular its dependence on the degree of saturation or water content, and therefore on suction. Nevertheless, existing studies on the behaviour of compacted materials are focused mainly on investigating how suction affects compression behaviour and volume changes on wetting, and also shear strength [1].

Tensile strength usually is considered under the form of apparent cohesion. Is being accepted that shear angle is constant and therefore suction only affects the cohesive term [2-3]. Tensile strength can also be considered explicitly, for example as in Barcelona Basic Model [2]. In this case it is given by:

$$
p_{s}=-K s
$$

where $p_{s}$ is tensile strength, $s$ is suction and $K$ is a constant. Fig. 1 presents its contribution to tensile strength in this model defined based in Modified Cam Clay Model, both in $\left(\mathrm{p}^{*}, \mathrm{~s}\right)$ and $\left(\mathrm{p}^{*}, \mathrm{q}\right)$ spaces where, as usual, $p^{*}$ is net mean stress, LC is loading-collapse curve, $q$ is deviatoric stress and CSL is the Critical State Line with slope independent from suction.
A

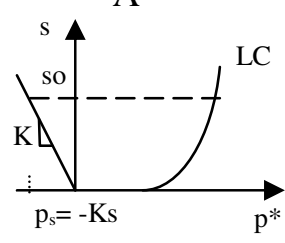

B

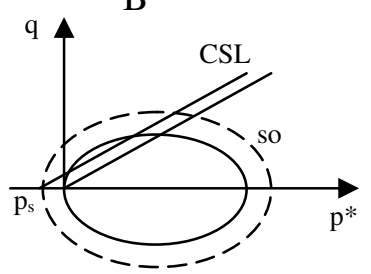

Fig. 1. Tensile strength (A) depending on suction and (B) how it affects shear strength.

This work focuses on investigating the tensile behaviour of compacted clays across a range of moisture contents. The material used is made of fragments of marls and the fine fraction resulting from their preparation. This material is abundant in the Iberian Peninsula and is used in embankments construction [4].

The influence of water content in tensile behaviour of compacted marls was investigated by performing diametral compression tests (Brazilian splitting tests), where axial deformations were measured besides strength. In addition, the study was completed with the analysis of other parameters such as the semi-contact 
angle created in the loaded area and the stiffness of the material, which also showed changes with water content.

\section{Materials and methods}

\subsection{Compacted marls and sample preparation}

The materials used are marls from Abadia formation in Portugal (upper Jurassic in age). Mineralogy analysis showed the presence of chlorite and gypsum, besides quartz, $\mathrm{CaCl}_{2}$ and mica. Some of its most relevant properties are a porosity of $37 \%$ for in situ water content of $17 \%$ (saturation degree of $77 \%$ ), liquid limit of $49 \%$, plastic index of $25 \%$ and volumetric weight of $27.4 \mathrm{kN} / \mathrm{m}^{3}$. Grading size distribution curve of the material used had $39 \%$ of fines (fraction passing in ASTM sieve \#200, with diameter $\mathrm{D}<0.075 \mathrm{~mm}$ ).

Previously to this work, standard compaction tests (ASTM D698, 1996) were carried out in order to establish the optimum water content $w_{\text {opt }}$ and the maximum dry density $\gamma_{d \text {,max }}[4]$, shown in Table 1.

Table 1. Compaction test results in Abadia marls [4].

\begin{tabular}{|c|c|c|}
\hline \multirow{2}{*}{ Material } & \multicolumn{2}{|c|}{ Standard Compaction } \\
\cline { 2 - 3 } & $w_{\text {opt }}(\%)$ & $\gamma_{d, \max }\left(\mathrm{kN} / \mathrm{m}^{3}\right)$ \\
\hline Marls & 16.50 & 17.80 \\
\hline
\end{tabular}

For the diametral compression tests, cylindrical samples were prepared manually by following the procedure illustrated in Fig. 2. After sieving the soil through the ASTM sieve \#4 (Fig. 2A, diameter of $5 \mathrm{~mm}$ ) the solid fraction was mixed with water (Fig. 2B-C) to reach optimum water content. Then, the overall was mixed manually (Fig. 2D) choosing a portion of the mixture (Fig. 2E, approximately $50 \mathrm{~g}$ ) for measuring initial water content of each sample $\left(w_{i}\right)$. The other portion (Fig. 2F, approximately 274.30 g) was compacted inside a cylindrical PVC mold (Fig. 2G-H) of diameter $D=70 \mathrm{~mm}$ until obtaining samples with thickness $t=35 \mathrm{~mm}$, because the Brazilian test standards recommends a ratio $t=D / 2$ (Fig. 2I).
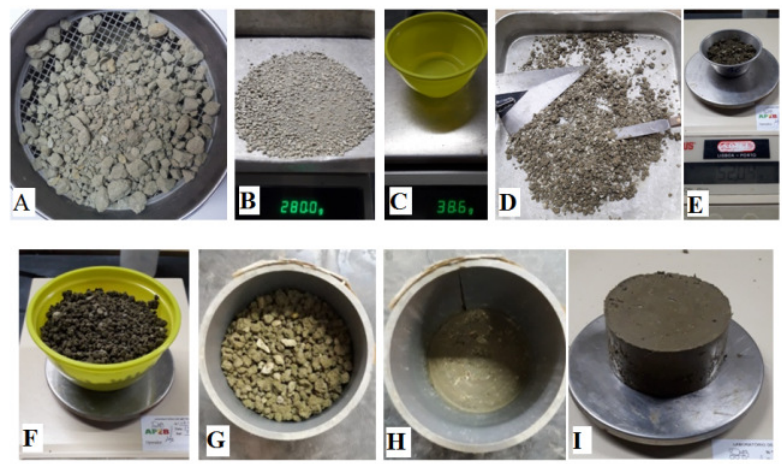

Fig. 2. Sample preparation steps.
In total 16 samples were prepared, each with initial water content of $16.50 \%$. In order to prepare the set of samples with the greatest similarity to each other, the solid fraction and the water were carefully weighted throughout the entire procedure.

Finally, due to the fact that the aim of this work is analyze the influence of the water content in the tensile strength, the samples were dried at environmental laboratory conditions (relative humidity $68 \%$ and temperature $19^{\circ} \mathrm{c}$, average values) until reaching different water contents. An homogeneous distribution in the sample's volume was assumed because the room was ventilated. Table 2 summarizes the final water contents tested taking into account that the mass of solid fraction is considered to keep constant along the time of drying. For each condition 4 samples were tested.

Table 2. Final water contents tested and time dried at environmental laboratory conditions (mean values)

\begin{tabular}{|c|c|}
\hline $\begin{array}{c}\text { Final water content } \\
w_{f}(\%)\end{array}$ & $\begin{array}{c}\text { Time dried at } \\
\text { environmental } \\
\text { conditions (h) }\end{array}$ \\
\hline 16.09 & 0 \\
\hline 15.05 & 3 \\
\hline 10.31 & 18 \\
\hline 5.04 & 27 \\
\hline
\end{tabular}

\subsection{Suction and water retention curve}

The water retention curve (WRC) of the compacted material was also determined. This curve translates the relationship between total suction $(\Psi)$ (or water potential) and the degree of saturation, which can be expressed as gravimetric water content or volumetric water content.

As well known, total suction can be defined as a measure of the energy required to remove water from the material. It is the sum of matric suction (associated to capillary forces) and osmotic suction (associated to the presence of dissolved salts) and depends on geometrical factors such as pore size, shape and distribution [5]. In practical terms for the objectives of the present work, total suction (also named total potential) is only due to the matric component, and can be interpreted as the force per unit area necessary to remove water, or the adherence force per unit area between the water and the solid particles of the material.

Numerous techniques have been proposed for the measurement of soil suction [6]. In this work, the total suction in each sample tested was measured with a Water Dewpoint Potentiometer WP4 device (Fig. 3). 


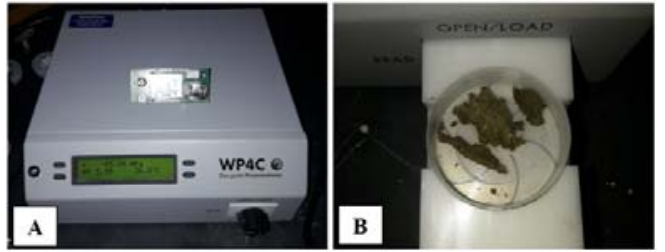

Fig. 3. A. Water Dewpoint Potentiometer WP4 device and b. detail of the portion of the sample measured.

WP4 equipment measures water potential (or total suction) by determining the relative humidity of the air above a sample in an enclosed chamber (in agreement with ASTM 6836). For this, the Kelvin's law [5] which relates total suction $(\Psi)$ and relative humidity $(R H)$ is considered:

$$
\Psi=-\frac{R T \rho_{w}}{M_{w}} \ln (R H)
$$

where $R$ the gas constant $\left(8.3143 \mathrm{~J} \mathrm{~mol}^{-1} \mathrm{~K}^{-1}\right), T$ the absolute temperature $(\mathrm{K}), \rho_{w}$ the density of pure water $\left(998 \mathrm{~kg} / \mathrm{m}^{3}\right.$ at $\left.293 \mathrm{~K}\right)$ and $M_{w}$ the molecular mass of water $(0.01801 \mathrm{~kg} / \mathrm{mol})$.

Once inside the WP4's sealed chamber, where temperature is measured, the water in the sample evaporates until reaching equilibrium with the air and condensates in a small chilled mirror placed inside the equipment. At dewpoint, detected using a laser beam scanning the mirror, the WP4 measures both mirror and sample temperature with $0.001^{\circ} \mathrm{C}$ accuracy. This allows the WP4 to deliver accurate total potential readings in $0.1 \mathrm{MPa}$ to $300 \mathrm{MPa}$ range. Cardoso et al. [7] performed an extensive description of the equipment as well as the calibration protocols.

\subsection{Diametral compression tests (Brazilian splitting tests)}

Brazilian splitting tests were carried out to measure the tensile strength according to the samples water content. The procedure ([8-9]) is widely used in brittle materials such as rocks and concrete, because is easy to implement and offers a reliable value of tensile strength, despite the fact that the determination of this parameter is carried out in an indirect way.

The concept of the test consists on loading a disc specimen along its vertical axis, resulting in the development of tensile stresses perpendicular to the line of load application.

Tensile strength $\left(\sigma_{t}\right)$ is obtained by using the following expression (assuming homogeneous load distribution):

$$
\sigma_{t}=\frac{2 F}{\pi D t}
$$

where $F$ is force at failure, and $D$ and $t$ are the diameter and thickness of the sample, respectively. In strict terms, Eq.(3) corresponds with the value of the tensile (or minimum) principal stress at the center of the disc, where is assumed to begin the failure.
Brazilian tests were carried out in a GDS triaxial soil testing system, in which the axial load and vertical displacements were registered, respectively, with a load cell (loading capacity of $8 \mathrm{kN}$, enough for the marls tested) and a LVDT. Moreover, the tests were recorded with a camera in order to visualize the whole failure process. The experimental setup for the Brazilian test, including the camera and the loading and the axial displacement systems are shown in Fig. 4.

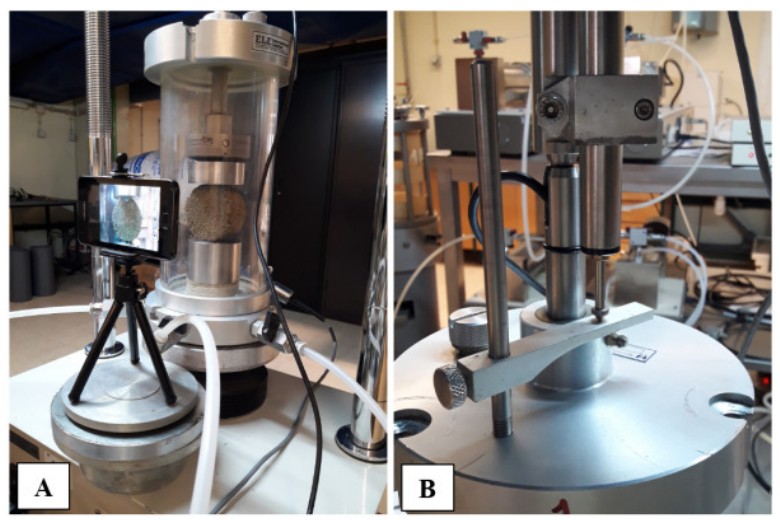

Fig. 4. A. Experimental setup for the Brazilian test. B. Axial displacement system in detail.

The indirect tensile test was carried out according to the ASTM D3967 standard [10], where the load is applied by using flat platens, with a constant rate of loading of $1 \mathrm{~mm} / \mathrm{min}$, since it guarantees the failure within 1 to 10 minutes as the standard recommends.

In each sample tested under diametral compression, total suction was measured by breaking the cylindrical samples in portions of lower size (according to the dimensions of the WP4's cup, also in Fig. 3). Finally, each portion was dried in a ventilated oven at $105^{\circ} \mathrm{C}$ for $24 \mathrm{~h}$ in order to obtain the real water content tested.

\section{Experimental results}

\subsection{Water retention curve}

The drying branch of the water retention curve of compacted marls is presented in Fig. 5 in terms of degree of saturation and of water content. Constant void ratio was assumed to convert the measured water content into degree of saturation.

Experimental data was fitted using Van Genuchten equation [11], which is one of the most used for geotechnical purposes due to its simplicity. It is defined by the following equation:

$$
S_{r}=\left[1+\left(\frac{\Psi}{P}\right)^{\frac{1}{1-\lambda}}\right]^{-\lambda}
$$

where $S r$ is the degree of saturation, $\Psi$ is the total suction and terms $P$ and $\lambda$ are constants to be determined with the experimental results. Parameters $P$ and $\lambda$ were calibrated fitting the experimental data to the curve defined by Eq. (4). A good agreement is reached when 
adopting values of $P=0.70 \mathrm{MPa}$ and $\lambda=0.24$, also presented in Fig. 5.
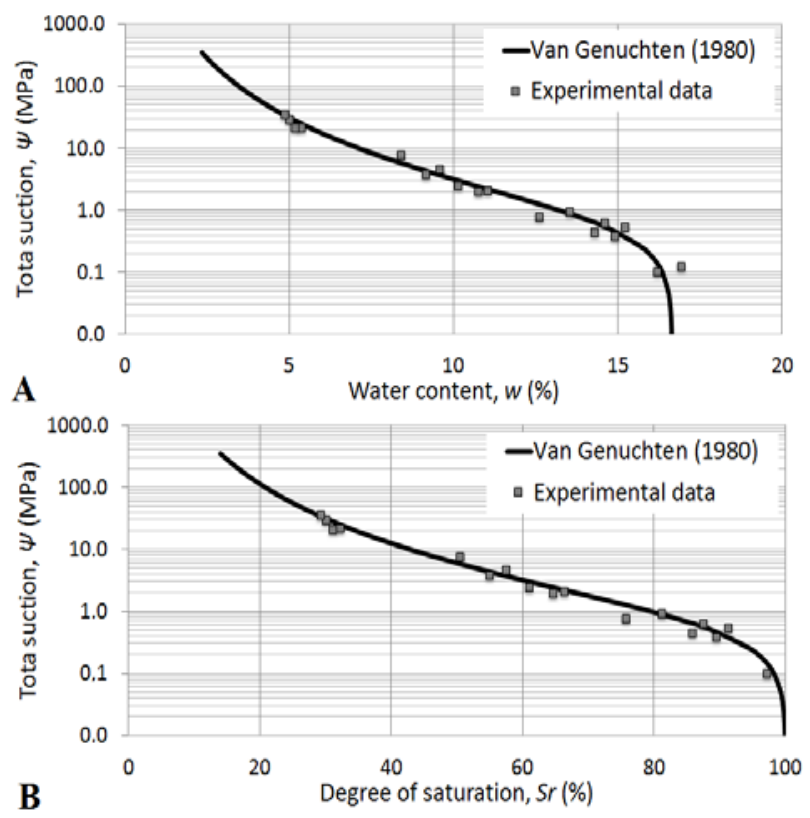

Fig. 5. Drying branch of the water retention curve in terms of (gravimetric) water content (A) and degree of saturation (B).

By considering the water retention curve obtained, it is possible to assert that the tests carried in compacted marls under diametral compression include the three stages that occur along the drying of the material: near saturation and below the air entry value, where gas phase is discontinuous; transitional zone, in which liquid and gas exist and both have continuity; and a residual zone near the residual degree of saturation, in which there is no continuity of the liquid phase.

\subsection{Brazilian splitting tests}

\subsubsection{Tensile strength}

Fracture patterns obtained in Brazilian tests according to compaction water content are presented in Fig. 6. It can be seen in this figure that all specimens fractured along a single central plane.

A tendency for the crack to develop only on one face was observed in some samples as well. It can be due to the lack of uniformity along the thickness of the samples, which implies that fracture is conditioned by the compaction process during the sample preparation. Nevertheless, from technical purposes in this work, the tensile strength of the material has been determined using Eq.(3) and the results are presented in Fig. 7.

As observed in Fig.7, and as expected, tensile strength of compacted marls decreases with increasing of water content (Fig. 7A), or decreases as total suction decreases (Fig. 7B). The variation of tensile strength is significant: for the lowest water content tested $\left(w_{f}=5.04 \%\right)$ the tensile strength is about four times higher than the value measured on the samples with the highest water content tested $\left(w_{f}=16.09 \%\right)$. A good agreement was reached, with correlation coefficients
$\left(\mathrm{R}^{2}\right)$ higher than 0.90. Also, the values of tensile strength obtained show a low dispersion of the set samples tested for each water content. In addition, a logarithm relationship was found between tensile strength and suction, alternative to a linear one such as eq. 1 [2].

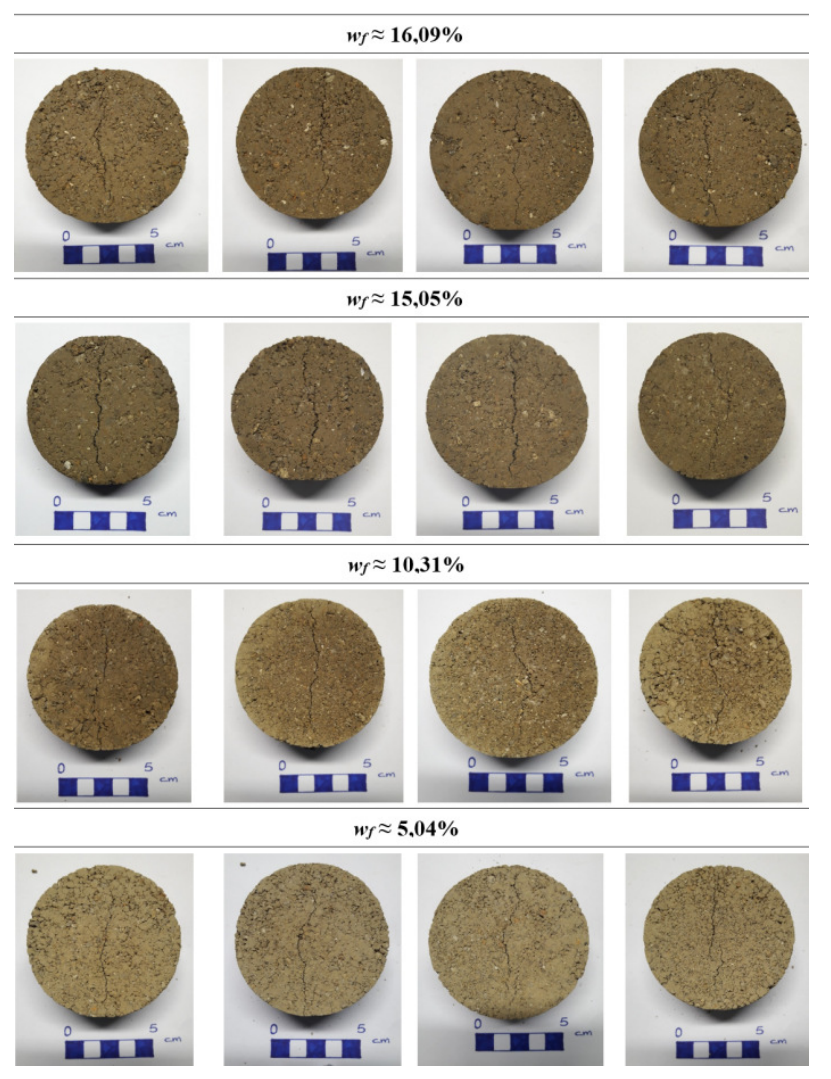

Fig. 6. Fracture patterns of the samples tested with different water contents.
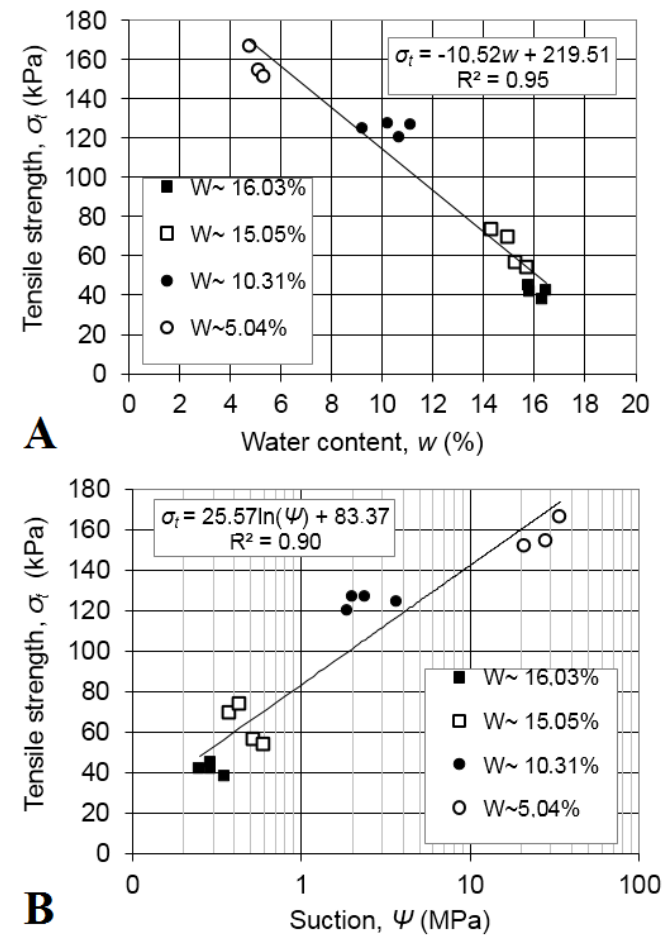

Fig.7. Relationship between tensile strength of compacted marls and A. Water content, $w$ and B. Total suction $(\Psi)$. 
Camera recording of the entire fracture process allowed to observe that failure does not always start in the center of the disc, especially on the samples with low water content. This effect is sometimes observed in brittle materials, and especially when the test is carried out with flat platens [12]. It can be explained by the relative stiffnesses of the material tested and that of the platens of the loading system (i.e. steel). Stiff plane platens tend to generate high stresses concentrated in the load area, which induce the initial failure in that zone.

For that reason, another two parameters were investigated in the present work: the stiffness and the semi-contact angle created in the loaded area.

\subsubsection{Stiffness and semi-contact angle}

The stiffness modulus can be obtained from the loading stress-strain curves. This parameter is the gradient of the straight line by plotting the tensile stress induced in the sample during the test versus the strain produced by the force applied along the same direction (measured through LVDT sensor, for simplification considered to be equal to the relationship between the vertical displacement and initial diameter). Fig. 8 represents different curves of tensile stress versus strain for the different water content values.

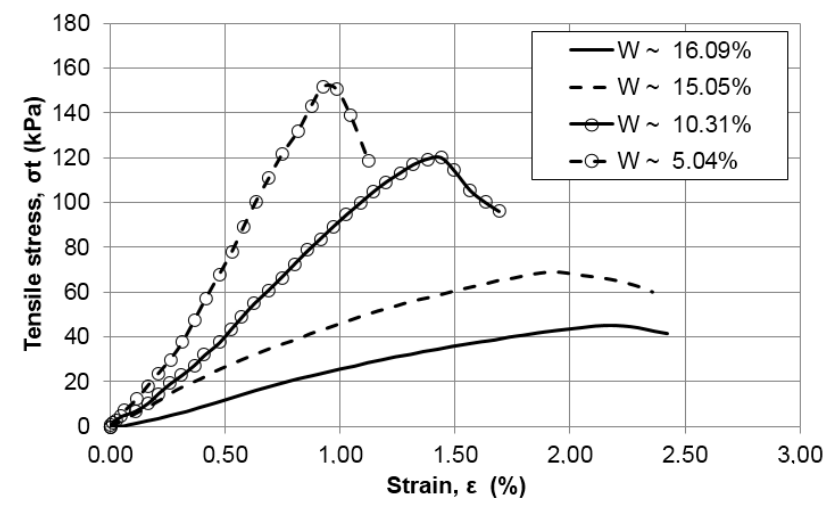

Fig. 8. Tensile stress versus strain curves for different water contents (a representative test for each water content is shown).

As presented in Fig. 8, a marked peak is observed for the driest samples, indicating a transition in behaviour from ductile $\left(w_{f}=16.09 \%\right)$ to more brittle $\left(w_{f}=5.04 \%\right)$. As expected, as the water content decreases the gradient increases, leading to an increment in the stiffness modulus of the material. In this work this modulus was computed as the slope of the tangent to the curves at the point corresponding to half maximum tensile stress reached. The mean values found for all different water contents are presented in Table 3 . It can be seen that the stiffness modulus measured on the driest samples is about seven times larger than those measured on the wettest ones.

Considering now the semi-contact angle, $\alpha$, it is obtained accordingly with Fig. 9. The material deforms in the contact between the flat platens and the disc as the load is increased during the test, resulting an increment in the load area and thus, of the semi-contact angle. The angles measured in each specimen tested are presented in Table 3. As expected, because the material stiffens when dried, semi-contact angle decreases with decreasing water content.

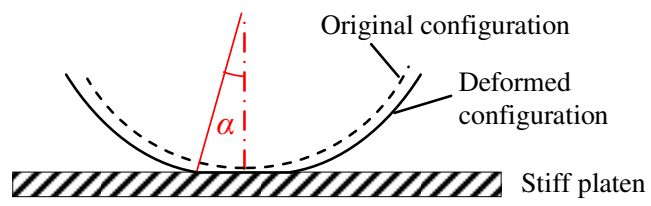

Fig. 9. Semi-contact angle $\alpha$.

Table 3. Stiffness modulus and semi-contact angles according to the final water contents tested (mean values)

\begin{tabular}{|c|c|c|}
\hline $\begin{array}{c}\text { Final water } \\
\text { content } w_{f}(\%)\end{array}$ & $\begin{array}{c}\text { Stiffness } \\
\text { Modulus (MPa) }\end{array}$ & $\begin{array}{c}\text { Semi-contact } \\
\text { angle } \alpha\left({ }^{\circ}\right)\end{array}$ \\
\hline 16.09 & 2.28 & 14.26 \\
\hline 15.05 & 3.66 & 14.14 \\
\hline 10.31 & 10.74 & 10.51 \\
\hline 5.04 & 17.55 & 7.08 \\
\hline
\end{tabular}

The variation in contact angle may be related with the position of the initial failure, because different investigations have found a relation between the contact angle created in the loaded area and the point where the rupture starts. According to Garcia-Fernandez et al [13], as the semi-contact angle decreases, the initial failure is closer to the load zone. This means that the material is more brittle with water contents of $5.04 \%$, but at the same time increases the probability to start the failure close to the load area. For this reason, different researchers suggest to carry out the test with curved jaw, in order to increase the contact area and decreasing the stress concentration in the boundary of the disc.

\section{Conclusions}

The mechanical behaviour of fragments of Abadia marls compacted with different water contents was analysed when they were subjected to diametral compression. The following main conclusions can be taken:

- Tensile strength of compacted marls decreases with increasing water content. The value of tensile strength for $w_{f}=5.04 \%$ is about four times larger than for $w_{f}=16.09 \%$.

- The material changes its behaviour from ductile to more brittle as the water content decreases. It causes an increment up to seven times in the stiffness modulus of the material.

- The variation of the stiffness according to the water content is related with the modification of the semicontact angle in the loaded area because the material deforms. Because the material stiffens when dried, semicontact angle decreases with decreasing water content.

- Changes in the semi-contact angle affect the condition the point where failure initiates in the samples. Such was not investigated deeper. 
To conclude, the knowledge on the behaviour of compacted materials is fundamental when they are used in the construction of earth structures. Existing studies are focused mainly on compression and volume changes on wetting, and also shear strength, in particular concerning on how they are affected by suction changes. Tensile strength usually is not considered, but cannot be disregarded when analysing cracking and suction contribution to strength under the form of apparent cohesion. This paper contributes positively to increase this knowledge. Relationships such as the one presented can help to improve the prediction of changes in the behaviour of compacted materials, particularly important when the effects of their exposition to atmospheric actions are investigated.

\section{Acknowledgements}

The authors acknowledge the financial support of the $\mathrm{PhD}$ fellowship Severo Ochoa Program of the Government of the Principality of Asturias (PA-14-PF-BP14-067). C.C. GarciaFernandez is also grateful to Banco Santander for his Movility Programme for researchers of the University of Oviedo.

\section{References}

1. E. Alonso, R. Cardoso. FSCE, 4, 1-39 (2010)

2. E.E Alonso, A. Gens, A. Josa. Geotechnique, 40(3), 405-430 (1990)

3. S.K. Vanapalli, D.G. Fredlund, D. E. Pufahl, A. W. Clifton. Canadian Geotechnical Journal, 33(3), 379-392 (1996)

4. R. Cardoso. E. Maranha das Neves. Engineering Geology, 133-134, 76-84 (2012)

5. D.G. Fredlund, H. Rahardjo. Soil Mechanics for Unsaturated Soils, John Wiley and Sons, New York (1993)

6. E. Romero. $4^{\circ}$ Simpósio Brasileiro de solos não saturados. Porto Alegre, Brazil, 535-542 (2001)

7. R. Cardoso, E. Romero, A. Lima, A. Ferrari. Proceedings in Physics 113, 79-93 (2007)

8. F.L.L.B. Carneiro. Proceedings of the 5th Meeting of the Brazilian Association for Technical Rules. Sao Paulo, Brazil; 16 September, 126-129 (1943)

9. T. Akazawa. J Jpn Soc Civil Eng, 29, 777-787 (1943)

10. ASTM D3967-95a. American Society for Testing and Materials, ASTM. (2001)

11. M.T. Van Genuchten. SSSA, 44, 892-898 (1980)

12. J.A. Hudson, E.T. Brown, F. Rummel. Int J Rock Mech Min Sci, 9, 241-248 (1972)

13. C.C. Garcia-Fernandez, C. Gonzalez-Nicieza, M.I. Alvarez-Fernandez, R.A. Gutierrez-Moizant. Int J Rock Mech Min Sci, 103, 254-265 (2018) 